\title{
AS PESQUISAS SOBRE O EFEITO \\ DAS ESCOLAS: contribuições metodológicas \\ para a Sociologia da Educação
}

\author{
Maria Teresa Gonzaga Alves* \\ José Francisco Soares**
}

\begin{abstract}
Resumo: Este artigo apresenta as metodologias de análise utilizadas em uma pesquisa longitudinal, cujo objetivo foi medir o efeito das escolas de sete estabelecimentos de ensino públicos localizados em uma mesma região da cidade de Belo Horizonte, MG. As pesquisas sobre o efeito das escolas constituem uma área específica no campo da Sociologia da Educação, que investiga o impacto das escolas para desempenho acadêmico dos alunos, após o controle das características de origem social dos alunos e do contexto das escolas. Durante dois anos letivos, foram coletados dados quantitativos, através de testes e questionários respondidos pelos alunos das escolas selecionadas, e dados qualitativos, através entrevistas com familiares de alunos e profissionais das escolas. Para a análise desses dados foram incorporadas novas técnicas estatísticas. Os modelos da Teoria da Resposta ao Item (TRI) foram utilizados para estimar os escores longitudinais dos alunos e os seus respectivos níveis socioeconômicos; e os modelos de regressão multiníveis, para a análise de dados longitudinais e com diferentes níveis de agregação. Os dados qualitativos foram analisados em conjunto
\end{abstract}

\footnotetext{
Doutora em Educação pela Universidade Federal de Minas Gerais (UFMG) e mestre em Sociologia pela Universidade de São Paulo (USP). Pesquisadora do Programa de PósGraduação em Ciências Humanas: Sociologia e Política, da UFMG (Bolsista Prodoc) e do Grupo de Avaliação e Medidas Educacionais.E-mail: mtga@ufmg.br

** Doutor em Estatística pela University of Wisconsin-Madison. Professor do Departamento de Ciências Aplicadas à Educação, da Faculdade de Educação da UFMG. É presidente da Associação Brasileira de Avaliação Educacional (Abave).

Texto baseado em pesquisa de doutorado desenvolvida no Programa de Pós-Graduação em Educação da UFMG, que contou com o apoio do CNPq, por meio de bolsa de doutorado, e da Fundação Ford, por meio de doação feita ao Grupo de Avaliação e Medidas Educacionais da Faculdade de Educação (GAME/FAE) da UFMG.
}

Artigo recebido em $1^{\circ}$ dez. 2006 e aprovado em 26 fev. 2007. 
com os resultados quantitativos, o que foi facilitado pelo uso de uma ferramenta que possibilitou a integração de dados textuais e atributos numéricos. Os resultados mostraram que a análise do efeito das escolas através de dados longitudinais é ser mais justa para as escolas, porque mostra o seu impacto no processo de aprendizagem dos alunos. A análise dos dados qualitativos mostrou fatores escolares e familiares que impactam os resultados dos alunos e que contribuem para a estratificação escolar. Considerando o potencial que as pesquisas educacionais podem ter para as políticas públicas, o artigo conclui sobre a importância da escolha de modelos de análise adequados para a análise do efeito das escolas. Além disso, a pesquisa mostrou a viabilidade do uso integrado de dados obtidos através de metodologias quantitativa e qualitativa, paradigmas usualmente tratados como se fossem necessariamente opostos, e a relevância desse procedimento para a compreensão dos resultados gerais.

Palavras-chaves: Sociologia da Educação, efeito-escola, métodos quantitativos, métodos qualitativos.

\section{Introdução}

No Brasil, a utilização de metodologias quantitativas em pesquisas com temas vinculados à educação cresceu bastante desde meados dos anos 90. Isso vem ocorrendo devido à necessidade de se analisar os resultados educacionais do país, uma vez tendo sido alcançada, finalmente, a universalização do ensino fundamental, além do crescimento dos níveis médio e superior. Os levantamentos em larga escala para avaliação dos sistemas de ensino realizados pelos governos federal, estaduais e municipais - apesar de possuírem algumas limitações quanto ao desenho metodológico, conforme discutido por Franco (2001) - constituem fontes de dados empíricos para inúmeros trabalhos de pesquisas. ${ }^{1}$ Esses estudos vêm contribuindo para ampliar a compreensão sobre as desigualdades educacionais brasileiras e suas conseqüências em termos de estratificação social dentro do processo de expansão generalizada 
do ensino (Barbosa \& Fernandes, 2001; Soares et al., 2001; Soares, 2005; Soares \& Alves, 2003), que são temas centrais na Sociologia da Educação em escala mundial (Karabel \& Halsey, 1977; Halsey et al., 1998).

Apesar do crescente interesse público por esses estudos e do aumento da literatura especializada, o uso de metodologias quantitativas nas pesquisas sociológicas sobre temas educacionais continua restrito a poucos grupos no Brasil. De uma forma geral, desde a criação das faculdades de educação como uma área específica das Ciências Sociais, no final dos anos 60, as pesquisas nesse campo privilegiam as abordagens microssociais, sendo ainda incipiente a utilização de dados secundários obtidos em levantamentos censitários, demográficos e educacionais ou a produção de dados em maior escala nas pesquisas desenvolvidas nessa área (Costa \& Silva, 2003). As exceções são os grupos multidisciplinares voltados para a temática da avaliação educacional, formados na última década e que se especializaram em metodologias adequadas para análise do desempenho dos sistemas de ensino, ${ }^{2}$ e os estudos produzidos nos departamentos de Sociologia ou de Demografia, que, há muitos anos, analisam as relações entre escolaridade e desigualdades sociais, raciais, mobilidade social ou ocupacional (Fernandes, 2005; Hasenbalg \& Silva, 2000; Pastore \& Silva, 2000) ou a eficácia dos sistemas de ensino (Veiga \& Costa, 2002), a partir das estatísticas oficiais produzidas pelo Instituto Brasileiro de Geografia e Estatística ou outras.

A fim de contribuir para a discussão das abordagens de pesquisas em foco nas Ciências Sociais, neste texto apresentaremos as estratégias metodológicas utilizadas em uma pesquisa de doutorado cujo principal objetivo foi analisar o efeito das escolas para o processo de aprendizagem de seus alunos (Alves, 2006). ${ }^{3}$ Neste trabalho procuramos incorporar novas metodologias de análise para a pesquisa no campo da Sociologia da Educação, mobilizando 
abordagens quantitativas e qualitativas que consideramos pertinentes para responder às questões propostas pelo estudo. Os aspectos metodológicos da pesquisa constituem o foco principal deste texto.

Na próxima seção, apresentaremos, brevemente, a importância das metodologias quantitativas para a constituição da Sociologia da Educação como um campo de pesquisa, bem como as renovações na área e os recentes avanços metodológicos que impactaram a produção das Ciências Sociais de uma forma geral. Na seção seguinte, em vários tópicos, descrevemos as etapas metodológicas da pesquisa em foco, bem como as ferramentas de análise utilizadas em cada fase, exemplificando com alguns resultados. Concluímos o artigo com uma discussão sobre as contribuições metodológicas deste estudo para as pesquisas sociais.

\section{As bases empíricas na constituição da Sociologia da Educação}

Embora a temática educacional esteja presente nos clássicos da Sociologia desde os seus primórdios, notadamente pelo legado do sociólogo francês Émile Durkheim, reconhece-se que a institucionalização da Sociologia da Educação como uma disciplina acadêmica e um campo de pesquisa somente ocorreu após o fim da II Guerra. Um fator primordial para esse processo foi a disponibilidade de inúmeras fontes de dados empíricos obtidas através de grandes surveys educacionais realizados, sobretudo, na Inglaterra, nos Estados Unidos e na França, ao longo dos anos 50 e 60 (Forquin, 1995). A principal motivação dessas pesquisas era investigar o problema das desigualdades de acesso e de resultados escolares, um tema central no escopo das políticas de bem-estar social desses países, o que justificou o financiamento público para a maior parte dos estudos (Karabel \& Halsey, 1977). 
Essa fase da Sociologia, caracterizada como fase do empirismo metodológico, posteriormente foi alvo de muito criticismo por produzir trabalhos considerados frágeis do ponto de vista teórico, o que se explicaria pela forte dependência da patronagem estatal. As pesquisas também sofreram restrições metodológicas, principalmente em relação aos modelos correlacionais empregados, que eram considerados limitados para responder a algumas questões propostas pelos pesquisadores (Mosteller \& Moynihan, 1972). No entanto, os modelos de análise utilizados eram os possíveis na época, considerando os recursos teóricos e computacionais disponíveis.

Apesar disso, inegavelmente, esses dados empíricos propiciaram avanços teóricos e metodológicos consideráveis para as Ciências Sociais de uma forma geral, além da Sociologia da Educação, como os estudos sobre estratificação e mobilidade social, a Sociologia do Trabalho, da Família, e outras áreas. Certamente, os sociólogos franceses melhoraram bastante as suas possibilidades de análise sobre as desigualdades de trajetórias educacionais no sistema de ensino do país com os dados da demografia escolar produzidos pelo INED - Instituto Nacional de Estudos Educacionais - (Forquin, 1995). Da mesma forma, o conhecido Relatório Coleman foi fundamental para os norte-americanos compreenderem a importância dos fatores de origem social e o efeito da raça na explicação das desigualdades de resultados escolares (Coleman et al., 1966). Como salienta Nogueira (1990), a constituição do paradigma da reprodução - o conjunto de teorias fundamentais no campo da Sociologia da Educação para a análise das desigualdades educacionais (Bowles \& Gintis, 1976; Bourdieu \& Passeron, 1975) - seria simplesmente impensável sem os fatos estatísticos estabelecidos nesses anos. No entanto, do ponto de vista das políticas públicas educacionais, esses resultados alimentaram um forte pessimismo pedagógico, porque levaram à conclusão que "as escolas não fazem diferença", já que a explicação para os resultados educacionais deveria ser procurada fora das escolas, na origem social dos alunos. 
Essa fase profícua da Sociologia da Educação se seguiu a um período, a partir dos anos 70, de crise dos paradigmas teóricos e metodológicos dominantes (Dandurand \& Ollivier, 1991), que não apresentavam grandes novidades sobre as desigualdades educacionais, além das teses reprodutivistas, que, de certa forma, condenavam à esterilidade qualquer política pública voltada para as escolas. Visando romper com esse círculo vicioso, as pesquisas educacionais se abriram para novas perspectivas, incorporaram novos objetos (estudos sobre escolas e salas de aula, análise sobre as representações sociais dos professores, estudos de trajetórias escolares, por exemplo) e renovaram suas metodologias, passando a valorizar abordagens microssociais (abordagens etnológicas, o interacionismo simbólico e a etnometodologia), que, até então, tinham pouco espaço nas pesquisas da Sociologia da Educação (Zaten et al., 1995). Essas tendências se tornaram muito influentes até os dias atuais, notadamente no Brasil, e tiveram um impacto considerável nos resultados das pesquisas educacionais.

Em relação às escolas, o pessimismo pedagógico começou a ser questionado com a publicação de alguns estudos que disputavam as conclusões do Relatório Coleman e outros trabalhos semelhantes que deram destaque ao fato de, apesar da inquestionável influência dos fatores socioeconômicos sobre os resultados escolares, a variação entre as escolas, ainda que pequena, não poder ser negligenciada. Algumas escolas, dependendo de suas políticas e práticas pedagógicas, poderiam reduzir o efeito dos fatores estruturais (especialmente o nível socioeconômico) na determinação dos resultados dos alunos em termos de desempenho cognitivo ou comportamental (Rutter et al., 1979; Brookover at al., 1979). A principal diferença desses estudos em relação aos da geração anterior era o foco no contexto e nos processos escolares que ocorriam dentro da caixa-preta da escola. Para isso, as novas pesquisas incluíam, além dos surveys educacionais, estudos de caso em escolas excepcionais, ou seja, estabelecimentos que, apesar de terem um alunado com origem 
social desfavorecida, apresentavam resultados acima da média em relação a outras escolas semelhantes, combinando, frequentemente, metodologias quantitativa e qualitativa (Teddlie \& Reynolds, 2000).

A partir de meados dos anos 80 , houve um aumento considerável da literatura voltada para os estabelecimentos de ensino. Isso foi estimulado, por um lado, pelas reformas educacionais que ocorreram nos principais países produtores de pesquisa e que tornaram as escolas mais autônomas e, conseqüentemente, menos homogêneas entre si (Cousin, 2000). Por outro lado, o desenvolvimento de novas metodologias de análise, especialmente os modelos de regressão múltipla multiníveis, também conhecidos como modelos hierárquicos - e respectivos programas computacionais -, solucionaram os problemas teóricos e metodológicos que constituíam os principais pontos de crítica em relação aos estudos educacionais produzidos nas décadas anteriores, por exemplo, o Relatório Coleman.

De forma sintética, os modelos multiníveis medem a variabilidade nos resultados dos alunos que pode ser explicada por diferentes níveis de análise, por exemplo, a sala de aula, a escola, o sistema de ensino ou a unidade da federação. A novidade e a importância disso são sintetizadas nas palavras de Goldstein (2001, p. 96): "começamos a ver as ações dos individuais como mediadas pelas ações dos outros com os quais eles estão em contato e pelas instituições às quais eles pertencem". Isso não é possível com os modelos de análise tradicionais (os modelos de regressão múltipla), porque eles tratam os indivíduos como entidades que atuam de forma independente. Atualmente, os modelos multiníveis tornaramse o padrão para qualquer pesquisa que utilize dados em larga escala com diferentes níveis de agregação. ${ }^{4}$

Os modelos multinível tiveram grande influência no desenvolvimento das pesquisas sobre o efeito das escolas como uma linha específica da Sociologia da Educação. Esse tipo de 
investigação, basicamente, procura analisar o impacto dos processos escolares sobre os resultados dos alunos e para diminuir a diferença de resultados escolares entre grupos sociais, após o controle dos fatores macroestruturais associados ao contexto no qual o aluno está inserido. A literatura nesta linha de pesquisa é bastante extensa, por exemplo, os trabalhos de Bryk, Lee e Holland (1993), a respeito das escolas católicas nos Estados Unidos, e Willms e Somers (2001), sobre a qualidade e eqüidade dos sistemas de ensino latinoamericanos. A literatura sobre o efeito das escolas brasileiras começou a crescer bastante a partir do novo milênio, por exemplo, Alves e Soares (2006), Barbosa e Fernandes (2001), Soares e Alves (2003), Soares (2005) e Soares e Andrade (2006).

Além de contribuir com evidências quantitativas nas pesquisas sobre o efeito das escolas, os modelos multiníveis podem também influir na orientação de pesquisas com abordagem qualitativa em contextos específicos, porque os seus resultados possibilitam identificar escolas exemplares que apresentam resultados acima do esperado, considerando as condições sociais de seu alunado, e que se tornam dignos de estudos de casos. Por exemplo, o Grupo da Avaliação e Medidas Educacionais realizou uma pesquisa sobre os fatores associados ao desempenho de alunos em quatro escolas públicas mineiras, que foram selecionadas a partir dos resultados em avaliações sistêmicas (Soares, 2002).

\section{Pesquisas sobre o efeito das escolas: um exemplo}

\section{Dados da pesquisa}

O maior desafio para o estudo sobre o efeito das escolas no Brasil reside na obtenção de dados adequados para medir esse efeito em termos de aprendizagem (Franco, 2001). Nessa área de pesquisa, existe o consenso que se deve trabalhar com dados longitudinais, porque as escolas recebem alunos com níveis de conhecimento 
diferenciados e a aprendizagem dificilmente é uniforme no tempo, tampouco no indivíduo. Ela varia em função das características dos alunos, mas também em função da organização escolar e das práticas pedagógicas. Assim, o desenho longitudinal é considerado o formato mais apropriado para medir o efeito das escolas, porque permite investigar o impacto das escolas nos alunos em termos de aprendizagem, após o controle do nível de conhecimento inicial e as características dos alunos (Singer \& Willet, 2003; Seltzer et al., 2003).

Buscando preencher essa lacuna, esta pesquisa teve um desenho longitudinal. ${ }^{5}$ Em sete escolas públicas localizadas na mesma região da cidade de Belo Horizonte, Estado de Minas Gerais, durante dois anos foram realizadas três ondas de coleta de dados: duas no primeiro ano da pesquisa, quando os alunos estavam na $5^{\text {a }}$ série; e a última no final do segundo ano letivo, com os alunos na $6^{\text {a }}$ série. Em cada uma das três ondas, todos os alunos de todas as turmas responderam a testes de língua portuguesa (com ênfase em leitura e interpretação de texto) e de matemática e a um questionário contextual, para levantar informações sobre as características demográficas, socioeconômicas e culturais dos alunos e de suas respectivas famílias, itens sobre o percurso escolar e hábitos de estudo.

Participaram da pesquisa 1.194 alunos, distribuídos nas sete escolas. No entanto, menos de $50 \%$ desses alunos estiveram presentes nas três ondas, principalmente por mudanças no alunado das escolas de um ano para o outro devido a transferências ou retenções. A ausência de dados longitudinais completos para todos os alunos impôs que os modelos de análise fossem bastante parcimoniosos.

Por outro lado, o pequeno número de escolas e de alunos, comparativamente às amostras dos estudos em larga escala, ampliou as possibilidades de análise qualitativas junto aos sujeitos da pesquisa. Assim, em todas as escolas foram realizadas entrevistas com profissionais e com os familiares dos alunos. 
As entrevistas realizadas com os profissionais tiveram como objetivo analisar os processos internos e externos que impactam os resultados dos alunos (Franco et al, 2003; Soares et al., 2003). Realizamos 22 entrevistas, distribuídas entre representantes de cargos de direção, coordenação e professores que estavam em exercício nas turmas selecionadas no primeiro ou no segundo ano do estudo.

Entre as famílias, as entrevistas tiveram como eixo norteador a identificação de práticas e disposições familiares ligações direta e indiretamente à vida escolar dos filhos (Lahire, 1997; Lareau, 1989, 2003; Nogueira et al., 2000). Realizamos 38 entrevistas com famílias, selecionadas de acordo com o desempenho dos filhos/alunos nos testes aplicados nas escolas, considerando os resultados médios da turma e da escola e não do conjunto dos alunos pesquisados. Procuramos, assim, estabelecer um sentido para a nota no contexto em que ela ocorreu. Apesar das famílias entrevistadas não constituírem uma amostra aleatória das famílias atendidas por essas escolas, procuramos garantir uma proporção equilibrada em relação à distribuição dos resultados dos alunos, mantendo a representatividade de famílias de alunos em todos os níveis de desempenho.

\section{Medida da aprendizagem dos alunos}

Os testes respondidos pelos alunos foram compostos por itens pré-testados do Banco de Itens do Grupo de Avaliação e Medidas Educacionais (Game-UFMG), construído a partir de itens públicos usados pelo Sistema de Avaliação da Educação Básica (Saeb) e pelo projeto Nova Escola, ambos desenvolvidos pela Fundação Cesgranrio, ${ }^{6}$ além de itens elaborados pelos professores das escolas. $\mathrm{O}$ uso desses itens públicos possibilitou a equalização da escala de desempenho dos alunos da pesquisa com a escala do Saeb, ou seja, as duas escalas têm a mesma interpretação substantiva. ${ }^{7}$ 
Para a construção dessa escala, os escores dos alunos obtidos nos testes foram interpretados como proficiências, isto é, como uma evidência da aprendizagem expressa através de um parâmetro de modelo da Teoria da Resposta ao Item - TRI (Hambleton, 1993; Valle, 2000). Esses escores não se baseiam no número de acertos nos testes. Com a TRI, o escore de cada aluno é calculado ponderandose, com pesos empiricamente obtidos, os resultados de cada item dos testes. Os pesos usados refletem idéias simples como a de que um acerto em um item mais difícil fornece maior evidência de alto desempenho do que um acerto de um item fácil.

Na análise de dados longitudinais, a TRI apresenta grandes vantagens porque permite a expressão das proficiências dos alunos obtidas em diferentes momentos em uma mesma escala, que, neste caso, varia entre 100 e 500. O uso de escala única viabiliza a comparação temporal dos resultados uma vez que as mudanças na escala ao longo do tempo representam ganhos em termos de conhecimento ou de habilidades e não apenas mudanças na escala de medida (Seltzer et al., 1994). Para produzir a escala única válida ao longo do estudo, os testes aplicados nas três ondas mantiveram alguns itens em comum.

A equalização com a escala do Saeb também possibilitou a validação dos resultados da pesquisa. As proficiências obtidas pelos alunos no início do estudo longitudinal foram comparadas com os resultados divulgados sobre o desempenho das escolas em avaliações sistêmicas oficiais. ${ }^{8}$ Além disso, o uso da escala do Saeb para a expressão dos resultados permitiu avaliar se os resultados dos alunos poderiam ser considerados bons ou ruins. ${ }^{9}$

Os processo de cálculo dos escores dos alunos através de modelos da TRI e a equalização entre as ondas foram conduzidos com o uso do programa computacional BILOG-MG. ${ }^{10}$ Para a equalização com a escala do Saeb utilizamos o método de equalização média/ 
desvio-padrão descrito por Kolen e Brennan (1995), com o uso do programa computacional ST, desenvolvido por esses autores. Os detalhes sobre a produção dos escores dos alunos com o uso da TRI e a equalização das proficiências, bem como os algoritmos utilizados estão descritos em Alves (2006). ${ }^{11}$

\section{Medidas dos construtos explicativos}

O estudo do efeito das escolas depende do controle do perfil e composição socioeconômica do alunado, pois não faz sentido alocar o efeito desses fatores à escola. Nesse estudo, com base na literatura específica, consideramos o gênero, a defasagem idade-série e o nível socioeconômico dos alunos. ${ }^{12}$

As medidas desses fatores foram obtidas através das respostas dos alunos nos questionários. $\mathrm{O}$ fator gênero foi coletado diretamente através da variável sexo. A defasagem idade-série foi calculada através da adequação da idade do aluno (fornecida pela data de nascimento) à série cursada, de acordo com as faixas etárias definidas pelo município. Assim, alguns alunos têm idade adequada ou estão adiantados, porque entraram na escola mais cedo do que o normal, considerando o mês que nasceram, e outros estão com defasagem, devido à repetência ou abandono seguido de reingresso mais tarde.

Quanto ao nível socioeconômico, em pesquisas educacionais, geralmente procura-se medir esse fator pela informação sobre a ocupação dos pais, porque há uma forte correlação entre ocupação e renda familiar. Porém, é muito difícil obter essa informação através de questionários aplicados ao alunos muito novos. Alternativamente, há outras técnicas para a construção de indicadores do nível socioeconômico, por exemplo, o chamado Critério Brasil, utilizado principalmente pelas empresas de pesquisa de opinião, que se baseia na pontuação obtida a partir da vários itens de conforto doméstico e a escolaridade do chefe da família. 
Nesta pesquisa, incluímos nos questionários, com algumas adaptações, os itens do Critério Brasil para medir o nível socioeconômico. ${ }^{13}$ No entanto, a metodologia para construir esse índice não se baseou na pontuação ponderada dos itens como se faz no Critério Brasil. Utilizamos modelos da Teoria da Resposta ao Item (TRI) que, além de produzirem as proficiências dos alunos, também são muito úteis para medir construtos que não são diretamente observados.

A utilização da TRI para a medida de características latentes, como é o caso do nível socioeconômico, apresenta diversas vantagens (Soares \& Andrade, 2006; Soares, T. 2005). Nesta pesquisa, essa técnica foi especialmente útil para tratar os dados faltantes. Eventualmente, alguns alunos deixaram de responder itens do questionário. Na forma clássica de construção de índices, esses casos deveriam ser desconsiderados. No entanto, a TRI permite um tratamento natural dos dados faltantes porque os modelos conseguem estimar o construto com as informações disponíveis sem a necessidade de se lançar mão de alguma técnica artificial de preenchimento de dados ausentes. Nesse processo, utilizamos modelos específicos da TRI. Como os itens incluídos no questionário para a construção do indicador do nível socioeconômico têm respostas com diferentes níveis de gradações - ou seja, alguns itens têm resposta binária (presença ou ausência de um bem de conforto) e outros têm mais opções de resposta, como a escolaridade dos pais e o número de carros na casa do aluno -, utilizamos o programa computacional MULTILOG. ${ }^{14}$ Detalhes sobre a construção desse tipo de índice com respostas graduadas podem ser consultados em Soares e Andrade (2006).

\section{Preparação dos dados qualitativos}

A transcrição das entrevistas produziu um volume enorme de informações. Para a preparação dos dados qualitativos, seguindo o 
modelo proposto por Bogdan e Bilken (1994), criamos categorias de análise, que, nas primeiras leituras, foram definidas à luz dos construtos que orientaram os roteiros das entrevistas e outras surgiram a partir dos dados. Em seguida, as categorias foram refinadas em subcategorias e agrupadas segundo dimensões relevantes que emergiram na análise, o que nos permitiu alinhar os discursos, destacar pontos convergentes e divergentes e relacioná-los entre si e com os resultados dos alunos e das escolas.

Para o trabalho de codificação e criação de agrupamentos de categorias utilizamos como ferramenta o programa computacional NVivo (Richards, 2000), desenvolvido para auxiliar o trabalho de análise de dados qualitativos. Com o uso desse programa, o trabalho de armazenamento, organização e codificação dos dados qualitativos ficou mais produtivo. Mas a principal vantagem foi a possibilidade de utilizar uma metodologia de análise mista dos dados quantitativos e qualitativos, por meio do relacionamento das categorias de análise qualitativa como os atributo numéricos dos alunos obtidos através dos questionários e dos testes (Creswell, 2003). O uso do programa computacional facilitou o "diálogo" entre as duas bases de dados. Tendo esse programa como ferramenta, os dados quantitativos foram utilizados como filtro para a análise das entrevistas. Com isso, produzimos várias matrizes que sintetizavam as relações entre variáveis quantitativas e categorias textuais.

\section{Descrição dos resultados}

A descrição dos resultados constitui uma etapa prévia e fundamental para a análise de dados empíricos. Essa necessidade foi elaborada de forma precisa pelo sociólogo francês P. Bourdieu (2001, p. 29) quando ele diz que não é "possível apreender os espaços sociais de outra forma que não seja a de distribuições de propriedades entre indivíduos. É assim porque a informação 
acessivel está associada ao individuo". Nesse texto, Bourdieu sugere como recurso para a construção do objeto de pesquisa a elaboração de um quadro de caracteres, que nada mais é que um banco de dados onde cada linha representa, por exemplo, um aluno ou um estabelecimento de ensino, e as colunas contêm várias propriedades necessárias para caracterizá-los. Para o pesquisador, essa descrição leva-o a pensar relacionalmente sobre as unidades de análise e as suas propriedades.

Na pesquisa sobre o efeito das escolas, a descrição permite apreciar a variabilidade dos resultados dos alunos por escola e segundo os fatores considerados, isto é, o nível socioeconômico (NSE), o gênero, a defasagem idade-série e outros. Neste trabalho, as descrições, por meio de tabelas e gráficos foram feitas com um dos mais populares programas computacionais entre os cientistas sociais: o SPSS. ${ }^{15}$

Como exemplo, o Gráfico 1 mostra a descrição da evolução das médias das escolas (nomeadas como E1, E2, etc.) nos testes de matemática ao longo das três ondas. $\mathrm{O}$ intervalo de confiança para essas médias está em tabela no Apêndice. No gráfico, os aspectos mais interessantes são as trajetórias das médias das escolas e a redução da variabilidade entre elas. Na primeira onda, as escolas estavam, praticamente, divididas em dois grupos; mas, na segunda e na terceira onda, as escolas tornaram-se muito mais parecidas. Apesar de nos dois grandes grupos ter se mantido a distinção, ela não é mais tão forte como era no início do estudo, o que sugere que políticas e práticas das escolas inicialmente mais fracas podem ter contribuído para compensar as defasagens iniciais de seus alunos. A variabilidade dos resultados é um aspecto importante para analisar a desigualdade dos resultados dos alunos, mas a evolução ao longo do tempo constitui uma síntese mais justa para a análise do efeito das escolas. 


\section{Gráfico 1 - Evolução das médias de matemática por escola}

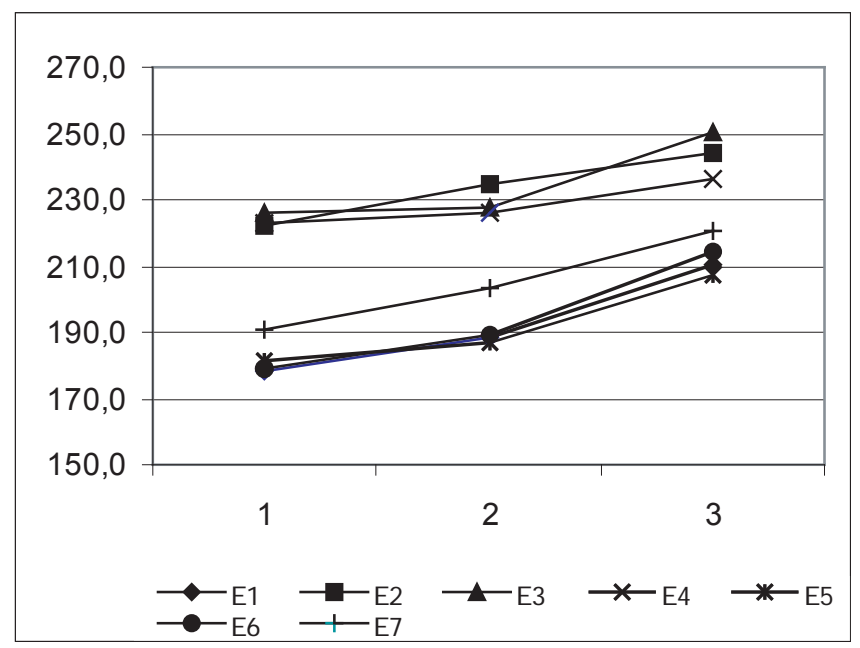

A interpretação desses resultados exige a incorporação do fator NSE, que é o mais forte preditor do desempenho escolar. Em qualquer contexto, é observado que os alunos de melhor nível socioeconômico têm maior probabilidade de se beneficiar de suas vantagens extra-escolares e de apresentar resultados melhores. O gráfico 2 mostra a distribuição do NSE entre as escolas pesquisadas. Com esse gráfico de caixas, também chamado de box-plot, ${ }^{16}$ notamos que as escolas se diferenciam em relação ao NSE dos seus alunos, apesar das caixas se interpolarem, o que significa que podemos encontrar alunos em todas as faixas de NSE nas sete escolas. A dispersão de valores é bem menor do que a verificada nos estudos em larga escala (que incluem escolas particulares e públicas), porque a maioria dos alunos se concentra entre os valores -1 a 1 , numa escala cujos valores típicos variam de -3 a 3 . Mas as escolas que têm as maiores proporções de aluno com NSE mais alto (E2, E3 e E4) são exatamente as escolas que apresentam os melhores resultados iniciais. 


\section{Gráfico 2 - Distribuição do NSE dos alunos por escola}

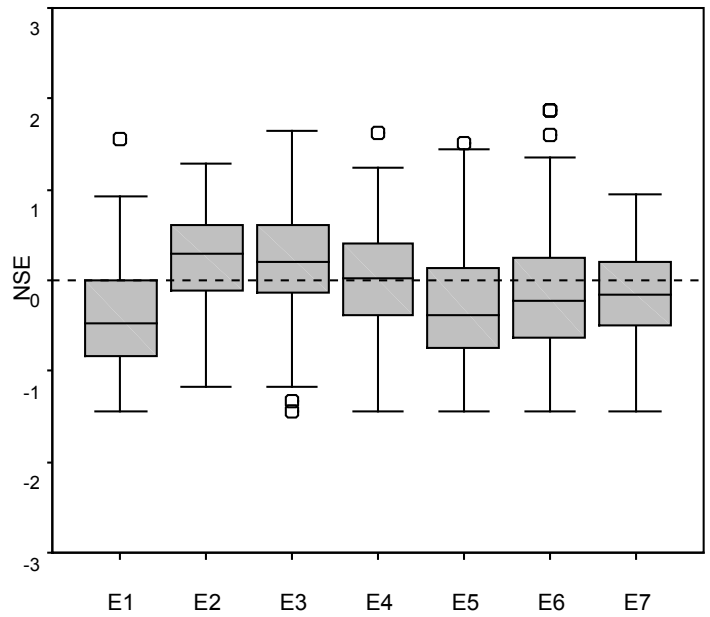

Além das descrições quantitativas em gráficos e tabelas, sempre que possível, os fatores quantitativos foram trianguladas com os dados textuais obtidos nas entrevistas com os profissionais das escolas e com os familiares dos alunos. A análise conjunta desses dados revelou associações interessantes entre os fatores escolares, as atitudes das famílias e os resultados dos alunos. Por exemplo, os quadros a seguir mostram estratos de análises sobre os valores e atitudes das famílias em relação à vida escolar dos filhos, segundo as faixas de desempenho dos alunos. No Quadro 1, estão algumas de famílias de alunos com alto desempenho e no Quadro 2, famílias de alunos com proficiências mais baixas.

De uma maneira geral, poucas famílias fazem algum tipo de investimento extra-escolar. O que apareceu como diferencial, especialmente no grupo com melhor desempenho, foram alguns alunos que freqüentaram cursinho preparatório para o Colégio Militar (escola federal que oferece ensino a partir da $5^{\text {a }}$ série do ensino fundamental) ou já foram alunos de escolas particulares. 
Além disso, considerando as condições econômicas dessas famílias, o gasto com transporte escolar pode ser considerado um investimento em educação. Em todas as faixas de desempenho encontramos famílias que fazem esse tipo de despesa, mas isso apareceu com mais freqüência nas famílias de alunos com desempenho alto.

Os investimentos podem ser associados a uma condição econômica um pouco melhor das famílias, mas em relação às atitudes dos pais também notamos diferenças mesmo entre famílias parecidas quanto aos fatores estruturais (nível socioeconômico, tipo de família, trajetória escolar dos filhos). No grupo de alunos de melhor desempenho, predominam os pais que têm altas expectativas em relação ao futuro dos filhos. No grupo de pior desempenho, encontramos mais famílias que têm um estilo "laissez-faire", ou seja, os pais interferem pouco na vida escolar do filho, ou então atribuem o sucesso ou fracasso escolar do filho às suas próprias atitudes e não à escola.

De uma forma geral, as análises integradas entre vários temas tratados nas entrevistas com os resultados dos alunos e das escolas mostraram que as atitudes das famílias têm impacto na estratificação escolar desde o momento de levar o filho para a escola, passando pelos investimentos escolarmente rentáveis, às atitudes e expectativas em relação à escolarização dos filhos.

As entrevistas com os profissionais das escolas também mostraram diferenças em relação ao projeto pedagógico, à rotina e ao funcionamento das escolas. Neste último ponto, destaca-se o problema da ausência ao trabalho por parte dos professores (com ou sem justificativa) que foi citado em todas as entrevistas, mas com muito mais ênfase nas escolas cujos alunos apresentaram resultados piores. 


\section{Quadro 1 - Investimentos educacionais e atitude dos pais de alunos com desempenho mais alto}

\begin{tabular}{|c|c|c|}
\hline $\begin{array}{c}\text { Aluno } \\
\text { (escola) }\end{array}$ & Investimentos & Atitudes \\
\hline Elisa (1) & $\begin{array}{l}\text { - Cursinho para o } \\
\text { Colégio Militar; } \\
\text { - Já fez curso de in- } \\
\text { glês; } \\
\text { - Já estudou em es- } \\
\text { cola do SESI; } \\
\text { - Transporte Esco- } \\
\text { lar }\end{array}$ & $\begin{array}{l}\text { Monitoramento da vida escolar } \\
\text { "A noite tem esse momento junto. Aí } \\
\text { acompanha, pergunta como é que foi } \\
\text { o dia dela na escola, como é que foi lá } \\
\text { no cursinho [...], a gente acompanha } \\
\text { bastante, até por medo de acontecer } \\
\text { alguma coisa" }\end{array}$ \\
\hline Guilherme (2) & Transporte Escolar & $\begin{array}{l}\text { Altas expectativas } \\
\text { "Ás vezes, a gente questiona um } \\
\text { pouco [as notas que ele tira]. Eu falo: } \\
\text { 'mais aí você tinha que ter tirado } \\
\text { mais aqui, tá' [...]. Ele fala assim: 'é } \\
\text { mesmo, né mãe?". } \\
\text { Monitoramento da vida escolar } \\
\text { "Esse ano o Gui está muito inter- } \\
\text { essado na escola. É porque eu es- } \\
\text { tou ajudando muito nisso, a minha } \\
\text { presença está ajudando muito. É, } \\
\text { eu tenho mostrado muito pra ele o } \\
\text { valor da escola, do estudo, porque } \\
\text { ele tem que estudar [...] Ele estuda } \\
\text { com prazer, sabe? Eu mostro pra ele, } \\
\text { é, o porquê que é bom estudar. Então } \\
\text { ele está muito mais interessado, esse } \\
\text { ano [...] E eu estou muito mais pre- } \\
\text { sente”. }\end{array}$ \\
\hline Luana (3) & Transporte Escolar & $\begin{array}{l}\text { Altas expectativas } \\
\text { "Eu falo com ela: se você pode ter } \\
100 \% \text { de aproveitamento, porque } \\
\text { nós vamos ficar só com } 90 \%, 80 \% \text { e } \\
\text { vamos descendo? } \\
\text { Não, vamos procurar os } 100 \% \text {, } \\
\text { porque se você tem } 100 \% \text { de aprovei- } \\
\text { tamento é sinal que você aprendeu } \\
\text { e captou } 100 \% \text { do que foi passado } \\
\text { para você". } \\
\text { Monitoramento da vida escolar } \\
\text { Participação na escola }\end{array}$ \\
\hline
\end{tabular}




\section{Quadro 2 - Investimentos educacionais e atitude dos pais de alunos com desempenho mais baixo}

\begin{tabular}{|c|c|c|}
\hline $\begin{array}{l}\text { Aluno } \\
\text { (escola) }\end{array}$ & Investimentos & Atitudes \\
\hline Cristina (4) & $\begin{array}{l}\text { Vai para a escola } \\
\text { de ônibus }\end{array}$ & $\begin{array}{l}\text { Resultado depende do aluno/a: } \\
\text { Eu falo para eles: "aquilo que vocês que- } \\
\text { rem vocês conseguem, depende da força } \\
\text { de vontade." E a escola pública não está } \\
\text { com nada, isso ai todo mundo sabe. Ela } \\
\text { ajuda, mas se depender da escola pública } \\
\text { para concurso, você esquece [...], então, } \\
\text { depois que entrou esse negócio de plural } \\
\text { eu acho assim que o aluno tem que ser } \\
\text { muito esforçado. }\end{array}$ \\
\hline Tiago (5) & - & $\begin{array}{l}\text { Resultado depende do aluno/a: } \\
\text { O que faz uma boa escola, eu acho que } \\
\text { é os alunos mesmo, é o que infelizmente } \\
\text { não está tendo. Uns são bonzinhos, mas } \\
\text { vêm outros de outra área e você sabe que } \\
\text { se mistura piora tudo. Então eu acho que } \\
\text { a boa escola é tudo igual, por exemplo, } \\
\text { não adianta nada os professores às vezes } \\
\text { fazem da tripa ao coração. [...]. }\end{array}$ \\
\hline Giovanna (7) & - & $\begin{array}{l}\text { Resultado depende do aluno/a: } \\
\text { Lá é estadual [sobre a escola onde a filha } \\
\text { mais velha estuda], tanto que lá é mais } \\
\text { forte o ensino, apesar que quem faz a es- } \\
\text { cola não é o ensino, é o aluno". }\end{array}$ \\
\hline
\end{tabular}




\section{Construção de modelos de análise}

As descrições apresentadas na seção anterior apresentam uma visão parcial do fenômeno estudado. Os gráficos e tabelas têm boa capacidade descritiva, mas não permitem uma explicação dos resultados, porque o desempenho do aluno é fruto de muitos fatores que devem ser considerados, concomitantemente, ao se procurar explicar a trajetória dos alunos. Para isso, são necessários modelos de análise estatísticos para a explicação dos resultados longitudinais e para a investigação do efeito das escolas. Os modelos de regressão são os mais utilizados para se analisar a relação entre variáveis. Há vários tipos de modelos de regressão, definidos de acordo com o tipo de variável resposta e a estrutura dos dados que se pretende analisar.

Nesta pesquisa, utilizamos como ferramenta básica de análise os modelos multiníveis de regressão múltipla. Para a análise de dados longitudinais, os modelos multiníveis permitem uma grande flexibilidade, porque o intervalo entre as observações pode variar, assim como o número de observações. Os modelos multiníveis conseguem, por um lado, considerar todos os dados coletados e, ao mesmo tempo, incorporar a dependência existente entre as observações de um mesmo aluno (cada aluno pode ter dados longitudinais para uma, duas ou três ocasiões) e entre os alunos dentro das escolas.

Nos modelos multiníveis ajustados, as escolas, sendo apenas sete, não foram consideradas como um nível hierárquico, mas foram incluídas nos modelos de análise como variáveis indicadoras. Assim, os coeficientes das covariáveis associadas às escolas puderam ser interpretados como uma medida da diferença de seus respectivos efeitos em relação à escola tomada como referência.

Propusemos vários modelos de análise para explicar o desempenho dos alunos no início do estudo (status inicial), o seu 
progresso durante os dois anos, bem como o impacto das variáveis dos alunos (gênero, atraso escolar e NSE) e das escolas no status inicial e no progresso. Foge ao escopo deste trabalho apresentar detalhes técnicos sobre esses modelos, ${ }^{17}$ mas para os leitores interessados, no apêndice, apresentamos um exemplo dos modelos ajustados, para o qual utilizamos o software HLM. ${ }^{18}$ A Tabela 1 mostra os resultados do ajuste desse modelo. O efeito das escolas está representado pelos símbolos + (se positivo) ou - (se negativo), sendo que o número de símbolos indica se o efeito é muito forte, forte, moderado ou não significativo. Optamos por apresentar símbolos em vez dos coeficientes para não atribuir aos modelos uma capacidade explicativa que eles não têm, haja vista que este não foi um estudo experimental. Os coeficientes são parâmetros que variam dependendo do modelo ajustado, sendo mais importante observar a tendência, quando ela se mostra mais estável entre os vários modelos ajustados.

\section{Tabela 1 - Efeito das escolas no status inicial e no progresso após o controle do NSE, atraso escolar e gênero do aluno}

\begin{tabular}{cc|c}
\hline \multirow{2}{*}{ Escola } & \multicolumn{2}{c}{ Matemática } \\
\cline { 2 - 3 } E1 é referência & Status Inicial & Ganho \\
\cline { 2 - 3 } & ++++ & + \\
E2 & ++++ & - \\
E3 & ++++ & --- \\
E5 & ---- & ++ \\
E6 & --- & + \\
E7 & - & + \\
\hline
\end{tabular}

++++ ou ----, $\mathrm{p}<0,01 ;+++$ ou ---, $\mathrm{p}<0,05 ;+$ ou =, não significativo.

$\mathrm{Na}$ leitura dos resultados sobre o efeito das escolas, a Escola 1 (E1) é a referência, ou seja, o efeito positivo ou negativo 
é considerado em relação à média da escola-referência. $\mathrm{O}$ uso de modelos multiníveis para dados longitudinais foi importante para apreciar a taxa de progresso das escolas, após o controle do status inicial e das características dos alunos (NSE, defasagem e gênero). A perspectiva longitudinal mostrou resultados diferentes do que teríamos com uma análise transversal (com uma única medida). A principal novidade foi mostrar que status inicial mais alto não implica maior progresso. Em algumas escolas, que tinham médias iniciais mais baixas (E5, por exemplo), os alunos progrediram bem mais durante a pesquisa do que os alunos das escolas cujas médias iniciais eram mais altas (E4, principalmente). Por outro lado, as melhores escolas mostraram uma tendência de estabilidade no período final do estudo, apenas reproduzindo, de um ano para outro, os resultados iniciais.

As evidências qualitativas foram importantes para compreendermos esses resultados. Em relação às escolas que tinham mais desvantagens associadas ao contexto social, as que mais progrediram desenvolveram políticas e práticas que contribuíram para o progresso acadêmico dos alunos mais fracos, considerados prioritários nessas escolas. Como explicou uma professora de uma das escolas que apresentou efeito acima da média: "aqui é uma escola que inclui alguns e exclui outros. Eu sinto que alunos que estão acima da média eles não têm muito espaço não. Então a gente fica o tempo inteiro pensando nesses alunos que têm mais dificuldade [...]".

Quanto às escolas inicialmente melhores, a indicação é que elas apenas reproduziram, de um ano para outro, seus resultados que desde o início refletiam um alunado mais favorecido em relação ao nível socioeconômico. As evidências qualitativas sugerem que essas escolas, nos níveis mais altos de ensino, tendem a se tornar menos estimulantes e a perder seus melhores alunos, à medida que eles avançam. Pais de bons alunos entrevistados manifestaram a intenção 
de levar os filhos para outras escolas em busca de melhores condições de ensino, se não for possível no ensino fundamental, que seja no ensino médio. As escolas públicas federais e colégios particulares menos dispendiosos são as metas de muitas dessas famílias, como expressou uma mãe de aluna de alto desempenho: "ela está fazendo cursinho pro Colégio Militar. [...] Se ela não passar, olha eu estou com a intenção de procurar outra escola [...] vou ver se eu coloco eles numa escola particular. [Qual escola particular?] Ah, eu estou estudando [...] eu não tenho condições de pagar uma escola de quatrocentos reais, de quinhentos, oitocentos reais por mês, então, fora o material e outras coisas mais. Então, eu vou ver se eu acho uma escola com o nível bom, mesmo que seja mais longe e tudo".

\section{Discussão}

Cada sociedade escolhe, através de suas opções históricas, um patamar possível para o aprendizado de seus estudantes. Entretanto, em torno dessa estrutura há grande variação. Em sociedades desiguais, como o Brasil, o nível esperado de desempenho varia de forma acentuada com o nível socioeconômico. O sistema escolar sozinho não consegue mudar esta determinação social, mas diferentes escolas são mais ou menos bem-sucedidas em fazer com que os seus alunos tenham aprendizado melhor do que o esperado pelas suas condições sociais. Essas variações explicam o efeito das escolas.

Procuramos demonstrar, com esta pesquisa, a importância dos estudos sobre o efeito-escola e as vantagens dos dados longitudinais para esse tipo de investigação, porque eles permitem estimar o impacto das escolas sobre o processo de aprendizagem, após o controle dos fatores estruturais. A aprendizagem é central para a educação e para a escola, porque reflete os processos que ocorrem com os alunos durante o tempo em que eles estão na escola (Singer \& Willett, 2003). 
No Brasil, isso é particularmente relevante num momento em que algumas avaliações educacionais conduzidas pelo governo têm estimulado a produção, por parte da imprensa, de ranking entre estabelecimentos de ensino. ${ }^{19} \mathrm{~A}$ divulgação desse tipo de informação sem levar em conta as diferenças quanto ao perfil socioeconômico dos alunos, bem como as suas trajetórias de crescimento dentro das escolas pode incorrer em equívocos e produzir políticas públicas indesejadas ao não evidenciar escolas de fato eficazes, conforme vem sendo amplamente discutido na literatura da área (Franco, 2001; Goldstein, 1997; Seltzer et al., 2003).

Os resultados desta pesquisa mostraram que as diferenças entre as escolas se mantiveram ao longo do estudo, mas as suas médias gerais se aproximaram no final do período, o que é um resultado positivo em termos de políticas públicas visando à melhoria do ensino e à eqüidade educacional. Algumas escolas que inicialmente tinham resultados muito ruins conseguiram melhorar a aprendizagem dos seus alunos e outras, inicialmente melhores, tenderam a apenas reproduzir os resultados que já eram, em média, mais altos.

Isso não permite, no entanto, concluir que a estratificação escolar irá se alterar significativamente com o passar dos anos, principalmente se pensarmos no sistema como um todo. Se as escolas mais fracas se aproximam das melhores, estas, na medida em que se equiparam às outras, tendem a perder bons alunos para outras escolas, conforme constatamos nas entrevistas de pais de vários bons alunos. Isso se constitui uma forma muito sutil do efeito de seleção, envolvendo a ação dos sujeitos (as famílias dos alunos), mas que atua fortemente na produção de desigualdades escolares.

Conquanto esses resultados sejam relevantes, registramos que este estudo tem limitações. Por ser uma pesquisa piloto que inclui poucas escolas, os modelos de análise tiveram que ser bem parcimoniosos. Além disso, eles podem ter sofrido o problema de variáveis omitidas. Em outras palavras, outras variáveis que não foram incluídas nos modelos de análise poderiam explicar melhor 
a aprendizagem dos alunos ou o relacionamento entre as variáveis incluídas. Importante frisar também que devido à natureza desse estudo, não é possível tirar conclusões sobre causa e efeito em relação aos resultados apresentados.

Apesar disso, o estudo traz contribuições metodológicas importantes para as pesquisas no campo da Sociologia da Educação. A condução da pesquisa longitudinal, que, nas Ciências Sociais, não é nada trivial, revelou-se bastante complexa no campo educacional. As mudanças inesperadas na base de alunos dentro das escolas, de um ano para outro, principalmente por motivo de transferência, aponta a necessidade, em futuras pesquisas, de ampliação da unidade de análise. Esse problema sugere que um estudo longitudinal em larga escala deveria considerar os sistemas de ensino como base amostral em vez de escolas, para que os alunos pudessem ser acompanhados em caso de transferências. Naturalmente isso não tornaria o estudo menos complexo, pois exigiria a criação de uma identificação única dos alunos, mas certamente produziria dados mais completos e de melhor qualidade.

Outro aspecto relevante desta pesquisa foi a utilização de modelos de análise adequados para dados longitudinais. A TRI, que produziu as proficiências dos alunos em uma escala única para os diferentes momentos da trajetória escolar, e os modelos multiníveis, que descreveram as mudanças de desempenho do mesmo aluno ao longo do tempo, permitiram incorporar, nos modelos de análise, a dinâmica do processo de aprendizagem, bem como o efeito das escolas nesse processo. Isso é uma novidade em relação às escolas brasileiras, cujos resultados, quando conhecidos através de avaliações sistêmicas, dizem respeito ao aprendizado dos alunos no final dos ciclos de ensino, mas nada sabemos sobre o quanto os alunos progrediram graças ao efeito das escolas.

A utilização de métodos quantitativos e qualitativos de forma integrada ou colaborativa tornou-se um dos aspectos mais 
significativos da pesquisa. A essência da abordagem quantitativa é caracterizar a variabilidade inerente a qualquer sociedade humana (Xie, 2005). Por outro lado, a investigação qualitativa pode e certamente melhora a nossa compreensão sobre a variabilidade humana através da aproximação a unidades típicas (sujeitos, estabelecimentos de ensino ou instituições) que representam tal diversidade. Essa idéia foi elaborada por Lareau (1989), que sugere que a investigação qualitativa tenta preencher os "espaços vazios" deixados pelos modelos estatísticos, procurando compreender como as ações individuais são socialmente condicionadas, mas sem cair numa abordagem psicológica. Assim, os dados quantitativos e os dados qualitativos produzem descrições da realidade que são igualmente ricas, mas que se diferenciam pelo grau de proximidade. Por exemplo, neste estudo, observamos uma grande consonância entre o nível socioeconômico das escolas, medido através de indicadores do questionário do aluno, com a descrição sobre o perfil social das escolas feita pelos profissionais que nela trabalham. Esse resultado é muito relevante para as pesquisas educacionais em larga escala, porque mostra que, apesar de todas as dificuldades de preenchimento que um questionário auto-aplicado por alunos, o resultado ainda constitui uma boa medida.

Corroborando a crítica que Bourdieu faz ao "monismo metodológico", nesta pesquisa procuramos mobilizar as técnicas adequadas, dadas as condições de definição do objeto, que eram pertinentes e tinham condições práticas de uso (Bourdieu, 2001), de forma que os dados quantitativos e qualitativos se complementaram. Por um lado, o número de escolas e de observações pode ser considerado pequeno para uma pesquisa quantitativa. Mas, por outro lado, apesar da pesquisa não incluir outros métodos qualitativos usualmente utilizados em pesquisas educacionais (estudos de caso, etnografia, por exemplo) as evidências obtidas com 60 entrevistas foram bastante significativas para os objetivos desse estudo. Sem os dados qualitativos, a interpretação dos resultados seria muito mais pobre. 
Finalmente, o uso de programas computacionais como ferramenta de análise foi muito útil. Eles nos auxiliaram bastante a pensar sobre os dados. Mas, evidentemente, como qualquer pesquisa, a análise foi conduzida segundo nossa perspectiva teórica e nossas reflexões constantes a cerca dos resultados parciais e finais, independentemente do auxílio computacional.

\section{Notas}

1 No nível federal, o Instituto Nacional de Estudos e Pesquisas Educacionais (Inep), do Ministério da Educação (MEC), realiza, por exemplo: o Sistema de Avaliação da Educação Básica (Saeb); o Prova Brasil - a versão ampliada do Saeb implantada em 2005; o Exame Nacional de Desempenho dos Estudantes do Ensino Superior (conhecido como Provão); e o Exame Nacional do Ensino Médio (Enem). No nível dos Estados, há, por exemplo, o Sistema Mineiro de Avaliação Educacional (Simave) que acompanha o desempenho de todas as escolas públicas do Estado e de algumas redes municipais.

2 Principalmente os grupos formados por indução a partir do Programa de Apoio à Avaliação Institucional (Proav) da Coordenação de Aperfeiçoamento de Pessoal de Nível Superior (Capes), instituído em 1997, com o objetivo de formação de recursos humanos especializados nas modernas técnicas de avaliação educacional. Em 2006, a Capes lançou um edital semelhante no âmbito do Observatório da Educação.

3 Agradecemos a Luciana dos Reis Batista, assistente de pesquisa contratada graças ao apoio da Fundação Ford, cujo trabalho foi fundamental para a condução desta pesquisa.

4 As pesquisas educacionais foram fundamentais para a evolução dos modelos multiníveis. Dois dos mais conhecidos programas computacionais para análise de dados organizados em estrutura hierárquica foram desenvolvidos no âmbito das faculdades de educação na Inglaterra e nos Estados Unidos. O programa Mlwin foi desenvolvido no Projeto de Modelos Multiníveis do Instituto de Educação da Universidade de Londres (Goldstein, 1995), e o HLM contou com a 
participação, no início, de pesquisadores das Faculdades de Educação da Universidade de Harvard, e depois da Universidade de Michigan e Universidade de Chicago (Raudenbush \& Bryk, 2002).

5 Esta foi uma pesquisa piloto - envolvendo poucas escolas - e de natureza exploratória. No Brasil, não há publicação de estudos com esses objetivos e características. O Inep realizou um estudo longitudinal para acompanhamento do desempenho escolar durante os anos de 1999 a 2003, no entanto, esses dados não foram ainda divulgados e publicados. Existe, atualmente, um projeto em andamento, o projeto Geração Escolar 2004 (Geres), que irá acompanhar uma coorte de alunos durante quatro anos a partir dos sete anos de idade. Detalhes sobre o Geres podem ser consultados no sítio: www.geres.ufmg.br.

6 Agradecemos a Nilma Fontanive, da Fundação Cesgranrio, a autorização para o uso dos itens que passaram a fazer parte do Banco de Itens do Game.

7 A interpretação pedagógica dessa escala indica o que o aluno sabe e consegue fazer com a proficiência que tem. Também informa quando o desempenho está em nível adequado, ou satisfatório ou apenas supera o que é básico. A metodologia de construção da proficiência do Saeb está descrita em Klein e Fontanive (1995).

8 Comparamos com os resultados divulgados pelo Sistema Mineiro de Avaliação Educacional (Simave) para alunos no nível da $4^{\mathrm{a}}$ série do ensino fundamental das mesmas escolas da amostra. Esses resultados são mais diretamente comparáveis porque a primeira onda desta pesquisa ocorreu logo depois da conclusão da $4^{\mathrm{a}}$ série (com os alunos no início da $5^{\text {a }}$ série) e o Simave ocorreu no final de 2003.

9 A escala do Saeb utiliza pontos de referência para mostrar às escolas e aos sistemas de ensino como está o desempenho de seus alunos. Especialistas que originalmente desenvolveram essa escala recomendam que todos os alunos deveriam atingir o nível "básico" em relação à série avaliada. Acima deste, o próximo ponto de corte delimita o nível "adequado", para o qual, no entanto, não há um consenso sobre o percentual de alunos que deveria atingir este nível. A interpretação desta escala é especialmente útil para o planejamento pedagógico porque ela 
mostra as habilidades que não foram desenvolvidas pelos alunos, mas que deveriam ter sido, para cada nível de ensino (Klein \& Fontanive, 1995).

10 BILOG-MG 3: Michele Zimowski, Eiji Muraki, Robert Mislevy e Darrell Bock (www.ssicentral.com)

11 Agradecemos àdisponibilidade do Ruben Klein, daFundação Cesgranrio, em responder nossas dúvidas sobre o processo de equalização.

12 A literatura aponta a relevância de se considerar também o fator racial nos estudos educacionais (Soares \& Alves, 2003). No entanto, devido à dificuldade de se coletar essa informação, a pergunta sobre a auto classificação racial dos alunos não foi incluída em todas as ondas, o que produziu muitos dados faltantes. Isso inviabilizou a inclusão dessa variável nos modelos de análise finais, quando consideramos apenas as variáveis para as quais havia informações para todos os alunos.

13 Itens considerados: a escolaridade dos pais, a posse de bens de conforto (automóvel, geladeira, vídeo, automóvel, computador, etc.) e a presença de empregada doméstica na residência.

14 MULTILOG: David Thissen, Wen-Hung Chen e Darrell Bock (www. ssicentral.com)

15 Originalmente, o SPSS, software desenvolvido nos anos 60 na Universidade de Stanford, Califórnia, EUA, significava Statistic Package for Social Science. Nos anos 70, o software saiu da academia para se tornar uma empresa. A partir dos anos 90, SPSS deixou de ser uma sigla para ser apenas um nome de uma marca comercial registrada. Atualmente, não há nenhuma referência direta nos materiais veiculados pela empresa SPSS (manuais, site, folhetos, etc.) ao público específico dos cientistas sociais. Principalmente a partir dos anos 90, quando foi lançada a versão para Windows, o SPSS abriu bastante seu foco, incluindo clientes bem variados, nos setores financeiro, industrial, comercial e público.

16 O gráfico de caixas (Box-plot) consiste em uma caixa e dois suportes. O meio da caixa é identificado pela mediana dos dados e marcado por 
uma linha horizontal. O extremo inferior é identificado pelo primeiro quartil (Q1) e o topo pelo terceiro quartil (Q3). Os suportes são as linhas que se estendem do topo e do fundo da caixa até os valores mais baixos e mais altos, na região definida pelos limites: inferior Q1 - 1.5 (Q3 - Q1) e superior Q1 + 1.5 (Q3 - Q1). Esse gráfico é interessante porque ele ajuda a visualizar a distribuição da variável representada, pois, simultaneamente, ele apresenta uma medida de tendência central (a mediana) que possibilita ter uma idéia dos valores típicos e, a partir do tamanho das caixas, podemos apreciar a amplitude dos valores da variável, ou seja, mostra a dispersão dos dados.

17 Há uma vasta literatura sobre o tema, por exemplo, Goldstein (1995) e Raudenbush e Bryk (2002), e também alguns trabalhos introdutórios publicados no Brasil: Goldstein (2001), Lee (2001) e Ferrão (2003).

18 HLM: Stephen. W. Raudenbush e Anthony Bryk (www.ssicentral. com).

19 Por exemplo, podem ser consultados no sítio do Inep (www.inep.gov. br, em 30 de junho de 2006), os resultados individuais por escola no Prova Brasil, que inclui as médias de todas as escolas públicas urbanas do país para os níveis de ensino da quarta e oitava séries de ensino fundamental, e os resultados individuais por escola no Exame Nacional do Ensino Médio (Enem), apesar deste exame ser voluntário para os concluintes e egressos desse nível de ensino.

School effectiveness research: methodological contributions to the Sociology of Education

Abstract: This paper presents the methods used in a school effects study of seven public schools from the same geographical area of Belo Horizonte, state capital of Minas Gerais - Brazil. The school effects research, a sub-area of Sociology of the Education, deals with the schools impact in student achievement, after the individual student socioeconomic status and pertinent school contexts variables are accounted for. During the two years that the study reported here lasted, the students' achievement was measured through their results 
in three tests and family and school staff context data through several interviews. Item Response Theory (IRT) models were used to estimate and equalize the students' proficiency in the three waves of the study. The socioeconomic status measure was constructed using the similar IRT models. Regression models for hierarchical data were adjusted to analyze the longitudinal data nested in different levels of aggregation. Software that allows the integration of textual and numerical data helped the analysis of the data collected through the interviews. Longitudinal data allows the use of more appropriate measures of school effects since it captures the student learning and not only the student achievement. The qualitative data analyses expose the school and familial factors that affects the results of the pupils and contribute for the pertaining to school stratification. Considering the potential impact of educational research on policy, the paper emphasizes the importance of using adequate models in the analysis of longitudinal data for the estimation of the school effects. Moreover, this study shows the viability of the integrated use of quantitative and qualitative methodologies, which are usually treated as opposite paradigms, and the relevance of this procedure for the understanding of the general results.

Keywords: Sociology of Education, school effects research, quantitative methods, qualitative methods.

\section{Referências}

ALVES, Maria Teresa Gonzaga. Efeito-escola e fatores associados ao progresso acadêmico dos alunos entre o início da $5^{a}$ série e o fim da $6^{a}$ série do Ensino Fundamental: um estudo longitudinal em escolas públicas no município de Belo Horizonte. Tese (Doutorado) - Universidade Federal de Minas Gerais, 2006.

ALVES, Maria Teresa Gonzaga; SOARES, José Francisco. Efeito-escola e estratificação escolar: o impacto das práticas de enturmação por nível de habilidade dos alunos. Educação em Revista, UFMG, Belo Horizonte, n. 45, p. 25-59, 2007.

BARBOSA, Maria Eugénia Ferrão; FERNANDES, Cristiano. A escola brasileira faz diferença? Uma investigação dos efeitos da escola na 
proficiência em matemática dos alunos da 4a série. In: FRANCO, C. (Ed.). Promoção, ciclos e avaliação educacional. Porto Alegre: ArtMed, 2001. p.155-172.

BOGDAN, Robert; BILKEN, Sari. Investigação qualitativa em educação: uma introdução à teoria e aos métodos. Porto: Porto Editora, 1994.

BOURDIEU, Pierre. O poder simbólico. 4. ed. Rio de Janeiro: Bertrand Brasil, 2001.

BOURDIEU Pierre; PASSERON, Jean-Claude. A reprodução: elementos para uma teoria do sistema de ensino. Rio de Janeiro: Francisco Alves, 1975.

BOWLES, Samuel; GINTIS, Herbert. Schooling in Capitalist America: educational reform and the contradictions of economic life. NewYork: Basic Books, 1976.

BROOKOVER, Wilbur. B. et al. Schools, social systems and student achievement: schools can make a difference. New York: Praeger, 1979.

BRYK, Anthony S., LEE, Valerie E.; HOLLAND, Peter B. Catholic Schools and the Common Good. Cambridge, MA: Harvard University Press, 1993.

COLEMAN, James S. et al. Equality of educational opportunity. Washington, DC: US Government Printing Office, 1966.

COUSIN, Ólivier. Politiques et effets-établissements dans l'enseignement secondaire. In: VAN-ZANTEN, A. (Ed.). L'école l'état des savoirs. Paris: La Découverte, 2000. p. 139-148.

COSTA, Márcio; SILVA, Graciella M. D. Amor e desprezo: o velho caso entre Sociologia e Educação no âmbito do GT-14. Revista Brasileira de Educação, n. 22, p. 101-120, 2003.

CRESWELL, John W. Research design: qualitative, quantitative, and mixed methods aproaches. Thousand Oaks: Sage, 2002.

DANDURAND, Pierre e OLLIVIER, Émile. Os paradigmas perdidos: ensaios sobre a sociologia da educação e seu objeto. Teoria \& Educação, v. 3, p. 120-142, 1991. 
FERNANDES, Danielle C. Estratificação educacional, origem socioeconômica e raça no brasil: as barreiras da cor In: PRÊMIO IPEA 40 anos. Brasília: IPEA, 2005. p. 21-72.

FERRÃO, Maria Eugénia. Introdução aos modelos de regressão multinível em educação. Campinas: Komedi, 2003.

FORQUIN, Jean-Claude. A Sociologia das desigualdades de acesso à educação: principais orientações, principais resultados desde 1965. In: FORQUIN, J. C. (Ed.). Sociologia da Educação: dez anos de pesquisas. Petrópolis: Vozes, 1995. p.19-78.

FRANCO, Creso. O SAEB: potencialidades, problemas e desafios. Revista Brasileira de Educação, v.17, p. 127-133, 2001.

FRANCO, Creso et al. O referencial teórico na construção dos questionários contextuais do SAEB 2001. Estudos em Avaliação Educacional, v. 28, p. 39-74, 2003.

GOLDSTEIN, Harvey. Multilevel statistical models 2. ed. London: Edward Arnold, 1995.

. Methods in school effectiveness research. School Effectiveness and School Improvement, v. 8, p. 369-395,1997.

GOLDSTEIN, Harvey. Modelos de realidade: novas abordagens para a compreensão de processos educacionais. In: FRANCO, C. (Ed.). Avaliação, ciclos e promoção na Educação. Porto Alegre: Artmed, 2001. p.84-99.

HALSEY, A. H.; LAUDER, Hugh; BROWN, Phillip; WELLS, Amy Stuart. The transformation of Education and society: an introduction. In: HALSEY, A. H. et al. Education: Culture, Economy and Society. New York: Oxford University Press, 1998. p. 1-44.

HASENBALG, Carlos; SILVA, Nelson Valle. Tendências de desigualdades educacional no Brasil. Dados, Revista de Ciências Sociais, v .43 , n. 3, p. 423-445, 2000.

KARABEL, Jerome; HALSEY, A. H. Introduction. In: KARABEL, J.; HALSEY, A. H. Power and ideology in Education. New York: Oxford University Press, 1977. p. 1-85. 
KLEIN, Ruben; FONTANIVE, Nilma Santos. Avaliação em larga escala: uma proposta inovadora. Em Aberto, v. 66, p. 29-35, 1995.

KOLEN, Michael J.; BRENNAN, Robert L. Test equating: methods and practices. New York: Springer Verlag, 1995.

LAHIRE, Bernard. Sucesso escolar nos meios populares: as razões do improvável. São Paulo, SP: Ática, 1997.

LAREAU, Anette. Home advantage: social class and parental intervention in elementary education. London: The Falmer Press, 1989.

. Unequal childhoods: class, race and family life. Berkeley, LA: University of Califórnia Press, 2003.

LEE, Valerie E. What are multilevel questions, and how might we explore them with quantitative methods? Estudos em Avaliação Educacional, v. 24, p. 31-45, 2001.

MOSTELLER, Frederick; MOYNIHAN, Daniel P. On equality of educational opportunity: Harvard University Faculty Seminar on the Coleman Report. New York: Random House, 1972.

NOGUEIRA, Maria Alice. A Sociologia da Educação do final dos anos 60/início dos anos 70: o nascimento do paradigma da reprodução. Em Aberto, v. 46, p. 49-59, 1990.

NOGUEIRA, Maria Alice; ROMANELLE, Geraldo; ZAGO, Nadir. Introdução. In: NOGUEIRA, M. A.; ROMANELLE, G. et al. (Ed.). Família e escola: trajetórias de escolarização em camadas médias e populares. Petrópolis: Vozes, 2000. p. 9-15.

PASTORE, José; SILVA, Nelson Valle. Mobilidade social no Brasil. São Paulo, Markron, 2000.

RAUDENBUSH, Stephen W.; BRYK, Anthony. Hierarchical linear models: applications and data analysis methods. 2. ed. Thousand Oaks: Sage Publications, 2002.

RICHARDS, Lyn. Using NVIVO in qualitative research. Doncaster, Victoria: QSR International Pty, 2000. 
RUTTER, Michael et al. Fifteen thousand hours: secondary schools and their effects on children. Somerst: Open Books, 1979.

SELTZER, Michael; CHOI, Kilchan; THUM, Yeow Meng. Examining relationships between where students start and how rapidly they progress: Using new developments in growth modeling to gain insight into the distribution of achievement within schools. Educational Evaluation and Policy Analysis, v. 25, n. 3, p. 263-286, 2003.

SELTZER, Michael H.; FRANK, Ken A.; BRYK, Anthony S. The metric matters: the sensitivity of conclusions about growth in student achievement to choice of metric. Educational Evaluation and Policy Analysis, v. 16, n.1, p. 41-49, 1994.

SINGER, Judith D.; WILLETT, John B. Applied longitudinal data analysis: modeling change and event occurrence. New York: Oxford University Press, 2003.

SOARES, José Francisco. O efeito da escola no desempenho cognitivo de seus alunos. In: SOUZA, A. M. (Ed.). Dimensões da avaliação educacional. Petrópolis: Vozes, 2005. p.174-204.

SOARES, José Francisco (Coord). Escola eficaz: um estudo de caso em três escolas da rede pública do Estado de Minas Gerais. Belo Horizonte: Game/FAE/UFMG, Segrac, 2002.

SOARES, José Francisco; ALVES, Maria Teresa Gonzaga. Desigualdades raciais no sistema brasileiro de educação básica. Educação $e$ Pesquisa, v. 29, n.1, p. 147-165, 2003.

SOARES, José Francisco, ALVES, Maria Teresa Gonzaga; MARI, Flávia de O. Avaliação de escolas de ensino básico. In: FREITAS, L. C. (Ed.). Avaliação de escolas e universidades. Campinas: Komedi, 2003. p.59-92.

SOARES, José Francisco; ANDRADE, Renato Júdice. Nível socioeconômico, qualidade e eqüidade das escolas de Belo 
Horizonte. Ensaio: Avaliação e Políticas Públicas em Educação, v. 14, n. 50, p. 107-126, 2006.

SOARES, Tuffi M. Utilização da teoria da resposta ao item na produção de indicadores sócio-econômicos. Pesquisa Operacional, v. 25, n. 1, p. 83-112, 2005.

TEDDLIE, Charles; REYNOLDS, David. The international handbook of school effectiveness research. London: Falmer Press, 2000.

VALLE, Rachel C. Teoria da resposta ao item. Estudos em Avaliação Educacional. v. 21, p. 7-91, 2000.

VEIGA, Laura; COSTA, Bruno Lazzoroitti Diniz. Eqüidade no ensino fundamental em Minas Gerais: uma avaliação exploratória. Mosaico, Revista da Fundação João Pinheiro, v. 1, n. 0, p. 42-59, 2002.

XIE, Yu. Methodological contradictions of contemporary Sociology. Michigan Quarterly Review, v. 44, n. 3, p. 506-511, 2005.

WILLMS, J Douglas; SOMERS, Marie-Andree. Family, classroom and school effects on children's educational outcomes in Latin America. International Journal of School Effectiveness and Improvement, v. 12 , n. 4, p. 409-445, 2001.

ZANTEN, Agnes Henriot-Van, DEROUET, Jean-Louis; SIROTÁ, Regine. Abordagens etnográficas em Sociologia da Educação: escola e comunidade, estabelecimento escolar, sala de aula. In: FORQUIN, J. C. (Ed.). Sociologia da Educação: dez anos de pesquisas. Petrópolis: Vozes, 1995. p.205-295. 


\section{APÊNDICE}

\section{Descrição dos dados longitudinais de Matemática}

\begin{tabular}{|c|c|c|c|c|c|c|c|c|c|}
\hline \multirow{2}{*}{ 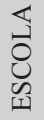 } & \multicolumn{3}{|c|}{ ONDA 1} & \multicolumn{3}{|c|}{ ONDA 2} & \multicolumn{3}{|c|}{ ONDA 3} \\
\hline & $\mathrm{N}$ & Mat_1 & IC 95\% & $\mathrm{N}$ & Mat_2 & IC 95\% & $\mathrm{N}$ & Mat_3 & IC $95 \%$ \\
\hline E1 & 131 & 178,5 & {$[171,6 ; 185,4]$} & 126 & 188,3 & {$[179,0 ; 197,6]$} & 125 & 210,4 & {$[201,3 ; 219,5]$} \\
\hline E2 & 136 & 222,5 & {$[215,3 ; 229,6]$} & 140 & 234,7 & {$[227,1 ; 242,2]$} & 150 & 244,4 & {$[236,6 ; 252,2]$} \\
\hline E3 & 97 & 226,4 & {$[218,5 ; 234,3]$} & 96 & 227,5 & {$[218,3 ; 236,7]$} & 102 & 250,5 & {$[242,2 ; 258,8]$} \\
\hline E4 & 169 & 222,8 & {$[215,6 ; 230,0]$} & 166 & 225,9 & {$[218,6 ; 233,1]$} & 175 & 236,2 & {$[229,2 ; 243,3]$} \\
\hline E5 & 103 & 181,1 & {$[172,3 ; 190,0]$} & 92 & 186,6 & {$[174,9 ; 198,3]$} & 119 & 207,6 & {$[198,3 ; 216,9]$} \\
\hline E6 & 148 & 179,2 & {$[171,1 ; 187,4]$} & 131 & 189,1 & {$[180,2 ; 198,1]$} & 125 & 214,4 & {$[205,7 ; 223,1]$} \\
\hline E7 & 87 & 190,8 & {$[181,0 ; 200,6]$} & 83 & 203,2 & {$[192,5 ; 213,8]$} & 95 & 220,5 & {$[211,3 ; 229,8]$} \\
\hline
\end{tabular}

Exemplo de modelo de análise multinível ajustado

Modelo de nível 1:

$\operatorname{Prof}_{\mathrm{ti}}=\beta_{0 \mathrm{i}}+\beta_{1}(\text { onda })_{\mathrm{i}}+\varepsilon_{\mathrm{i}}$

Modelo nível 2:

$$
\begin{aligned}
& \beta_{0 \mathrm{i}}=\gamma_{00}+\gamma_{01}(\mathrm{SEXO})+\gamma_{02}(\mathrm{NSE})+\gamma_{03}(\mathrm{DEFASAGEM})+ \\
& \gamma_{04}\left(\mathrm{DEF} \_\mathrm{REDE}\right)+\gamma_{05}\left(\mathrm{ESC} \_2\right)+\gamma_{06}\left(\mathrm{ESC} \_3\right)+\gamma_{07}\left(\mathrm{ESC} \_4\right) \\
& +\gamma_{08}\left(\mathrm{ESC}_{-} 5\right)+\gamma_{09}\left(\mathrm{ESC}_{-} 6\right)+\gamma_{010}\left(\mathrm{ESC}_{-} 7\right)+\mathrm{u}_{0 \mathrm{i}} \\
& \beta_{1}=\gamma_{10}+\gamma_{11}(\mathrm{SEXO})+\gamma_{12}(\mathrm{NSE})+\gamma_{13}(\mathrm{DEFASAGEM})+ \\
& \gamma_{14}\left(\mathrm{DEF} \_\mathrm{REDE}\right)+\gamma_{15}\left(\mathrm{ESC} \_2\right)+\gamma_{16}\left(\mathrm{ESC} \_3\right)+\gamma_{17}\left(\mathrm{ESC} \_4\right) \\
& +\gamma_{18}\left(\mathrm{ESC}_{-} 5\right)+\gamma_{19}\left(\mathrm{ESC}_{-} 6\right)+\gamma_{110}\left(\mathrm{ESC}_{-} 7\right)
\end{aligned}
$$

Os parâmetros desse modelo têm os seguintes significados substantivos: a primeira equação diz que a proficiência de um aluno 
i específico no tempo t pode ser descrita através de uma reta, na qual $\beta_{0 \mathrm{i}}$ é o valor médio daquele aluno para a onda $1(\mathrm{t}=0)$ e $\beta_{1}$ ganho médio entre as três ondas. Observa-se, como explicado acima, que o parâmetro $\mathrm{B}_{0 \mathrm{i}}$, varia por aluno e o parâmetro $\beta_{1}$ é o mesmo para todos os alunos. Esta restrição teve que ser aplicada por limitações dos dados, já que para mais de $50 \%$ dos casos o número de observações não alcançou o número ideal de pelo menos três. $\mathrm{O}$ índice t pode assumir os valores 0,1 ou 2, para as ondas 1,2 e 3 , respectivamente. A inclusão das variáveis abaixo listadas tanto em $\beta_{0 \mathrm{i}}$ como em $\beta_{1}$ permite avaliar o impacto de cada uma delas na onda 1 e nos ganhos, respectivamente.

\begin{tabular}{l|l}
\hline -SEXO & $\begin{array}{l}\text { Assume valores zero, para os meninos e } \\
1, \text { para as meninas; } \\
\text { O nível socioeconômico do aluno, em } \\
\text { uma escala cujos valores típicos variam } \\
-3 \text { a } 3 ;\end{array}$ \\
-NSE & $\begin{array}{l}\text { A defasagem idade-série pode assumir } \\
\text { valores zero, para alunos com idade } \\
\text { certa; 1, para o atraso de um ou mais } \\
\text { anos; } \\
\text { Variável de interação. A rede municipal } \\
\text { tem o valor zero, e a rede estadual o } \\
\text { valor 1; } \\
\text { Varáveis indicadoras das escolas. A } \\
\text { DEFASAGEM }\end{array}$ \\
\hline $\begin{array}{l}\text { ESC_2, ESC_3, ESC_4, } \\
\text { ESC_5, ESC_6 e ESC_7 }\end{array}$ & Escola 1 rência \\
\hline
\end{tabular}

